\title{
FRACIONAMENTO ISOTÓPICO DA ÁGUA DO SOLO DURANTE O PROCESSO DE EVAPORAÇÃO, EM PRESENÇA DE LENÇOL FREÁTICO
}

\author{
Paulo Rodolfo Leopoldo \\ Dept $^{\circ}$ de Engenharia Rural - \\ Faculdade de Ciências Agronômicas \\ Campus de Botucatu \\ Eiichi Matsui \\ Eneas Salati \\ CENA - Piracicaba - SP \\ Rubismar Stolf \\ Bolsista da C.N.E.N.
}

This experiment was conducted with columns of soil, constitued by alluvion sediment keeping a phreatic watertable at a depth of $40 \mathrm{~cm}$ and constant water supply, and its objective was to check the water behaviour as to its deuterium and oxigem content when moving from the lower layers to the upper layers, and consequent loss to the atmosphere through evaporation.

It was noted that the existing $D$ and

\begin{abstract}
$O$ experimento conduzido em colunas de solo, constituidas por sedimento aluvionar, com um lençol freático mantido a uma profundidade de $40 \mathrm{~cm}$ e constante suprimento de água, teve por objetivo verificar o comportamento da água quanto ao seu conteúdo de deutério e oxigênio, por ocasião de sua movimentação das camadas inferiores para as superiores e sua conseqüente perda para a atmosfera por evaporação.
\end{abstract}

Esse experimento demonstrou que o

\begin{abstract}
180 content in the water forming the phreativ watertable practically does not vary with this process.

In addition to the observations on soil columns, soil water from the Brasilian northeastern region was collected and analysed. The phreatic watertable at the collecting site lay at a depth of about $40.50 \mathrm{~cm}$. Preliminarily, it was noted that these results apparently indicate an excess evaporation, and are
\end{abstract}

\section{RESUMO}

teor de deutério e oxigênio 18 da água do lençol freático permanece, praticamente, constante por ocasiåo de sua movimentação ascendente através de uma coluna de solo.

Além da observação em colunas de solo, coletou-se e analisou-se também, a água do solo da região do Nordeste Brasileiro, em local onde o lencol freático se encontrava a uma profundidade de cerca de $40 \mathrm{~cm}$ a $60 \mathrm{~cm}$. Preliminarmente, observa-se que tais resultados also consistent with those obtained by other investigators, who proposed the use of stable isotopes to study problems related to salinization of water in this region.

The data now obtained are highly promising, but further studies on the region are required, taking up a deter mined region and correlating other data involved in the hydrological cicle.

aparentemente indicam uma evaporação excessiva, e estão também de acordo com outros pesquisadores que propõem o uso de isótopos estáveis nos estudos de problemas de salinização das águas da região.

Os dados ora obtidos foram bastante promissores, e cabe a continuação dos estudos na região, tomando-se em par* ticular uma determinada bacia e cor. relacionando outros dados envolvidos no ciclo hidrológico. 


\section{INTRODUÇ̃̃̃O}

A água livre, quando submetida ao processo de evaporação altera as suas relações isotópicas.

O mesmo era de se esperar com relação a água retida pelo solo e submetida a perda por evaporação.

No entanto, como pode ser observado em LEOPOLDO, SALATI e MATSUI (1974) as variações no conteúdo isotópico da água do solo ocorrem somente para aquelas retidas a altos potenciais, ou classicamente definidas como higroscópica. No intervalo entre saturação e ponto limite de água higroscópica o teor isotópico $\mathrm{da}$ água do solo permanece praticamente constante. Esses autores admitem que a ausência de fracionamento na água do solo se deve em razão da referida água mover-se ou estar retida através de poros capilares.

Tal observação está de acordo com aquelas feitas por GONFIANTINI et alii (1963) e ZIMMERMANN, et alii (1966) que afirmam a ausência de fracionamento isotópico nas águas que se movem através de vasos capilares de plantas.

No presente trabaiho simulou-se uma determinada situação, em que se tinha um lençol freático constante quanto a profundidade e suprimento, com objetivo de ser observado o comportamento do conteúdo isotópico durante o fluxo da água para atmosfera. O mesmo destina-se a obter novos subsídios para estudos no campo da hidro. logia, e principalmente para aqueles que estão sendo desenvolvidos pelo CENA em regiões do Nordeste Brasileiro. Sua importância se traduz nas observaçðes feitas por SALATI et alii (1971) que através de um levantamento preliminar das variaçes das concentraçôes de De e ${ }^{18}$ o em águas da região nordestina concluiram sobre a possibilidade de uso destes isótopos como traçadores no equacionamento de alguns problemas hidrológicos.

\section{MATERIAL e MÉTODO}

\subsection{Colunas de solo e lençol freático}

Preparou-se 5 colunas de solo, for. madas por anéis de tubo de PVC de 4", com $10 \mathrm{~cm}$ de altura cada um dos anéis. Cada coluna era constituída de 4 anéis, unidos entre si através de fita adesiva, de modo a formar uma coluna com $40 \mathrm{~cm}$ de altura.

$\mathrm{Na}$ amostragem das colunas empregou-se como material um sedimento aluvionar com $90,79 \%$ de areia, $2,37 \%$ de limo e $6,84 \%$ de argila.

Inicialmente, o sedimento aluvionar utilizado foi seco ao ar, desagregado, homogeneizado, passado por peneira de $2 \mathrm{~mm}$ e levado à estufa a $105-110^{\circ} \mathrm{C}$, até peso constante. $\mathrm{O}$ seu acondicionamento nas colunas, era acompanhado de vibraçóes para obter-se uma compactação uniforme, e colunas de solo homogêneas, quanto a estrutura e textura. O grau de uniformidade era medido através da determinação da densidade aparente para cada secção, ou seja, para cada anel da coluna, e o seu valor variou de 1,62 a $1,66 \mathrm{~g}$ de so$10 / \mathrm{cm}^{3}$

O lençol freático, alimentado por um reservatório à pressão atmosférica, foi mantido a uma profundidade constante de $40 \mathrm{~cm}$, com um suprimento de água também constante. (Fig. 1)

O sistema descrito, colunas e reservatórios, foram levados para uma casa de vegetação, onde ficaram submetidos à perda de água por evaporação. Diariamente, fazia-se o controle da quantidade de água evaporada, bem como o reabastecimento dos reservatórios, além do controle da temperatura e umidade relativa, através de um termohigrógrafo.

\subsection{Amostragem e extração da água do solo}

As amostras de solo para análise da água retida, foram obtidas em in tervalos de cada 7 dias, num período de 35 dias.

De cada coluna, escolhida ao acaso, por ocasião da amostragem, obtinha-se 4 amostras correspondentes aos perfis $0-10,10-20,20-30$ e $30-40 \mathrm{~cm}$ de pro. fundidade. Em todo experimento, obteve-se um total de 20 amostras, uma vez que foram utilizadas 5 colunas. Essas amostras eram acondicionadas em tubos de vidro, tipo tubo de ensaio, bem vedados.

Além das amostras de solo, coletouse também, no início duas amostras de água utilizada no suprimento das colunas.

A extração da água das amostras de solo foi feita aplicando-se o método desenvolvido por LEOPOLDO et alii (1973), variando-se apenas a fonte de aquecimento das amostras. $\mathrm{O}$ método em questão tem por princípio o aquecimento da amostra a $105-110^{\circ} \mathrm{C}$ e condensação da água extraída em um sistema operado à baixa pressão. $O$ tempo de operação do sistema variou de 3 a 4 horas, de acordo com o teor de umidade retido pelo solo. Na Figura 2 apresenta-se, em esquema, o sistema de extração da água do solo, utilizado no presente caso.

\subsection{Preparo da água extraida para} análise do conteúdo de deutério.

A água extraída era colocada em capilares, contendo cerca de 7 ul de água cada um. Esses capilares eram posteriormente utilizados em um siste- ma de decomposição da água pelo método do urânio metálico, através do qual se obtém lodo hidrogênio da amostra de água, na forma de gás. $\mathrm{Na}$ operação e uso do referido sistema, seguiu-se as indicaç̃es contidas em MATSUI ei alii (1971).

\subsection{Preparo da água extraida para} análise de conteúdo de oxigênio 18

No preparo das amostras de água para análise do oxigênio 18 utilizou-se de um sistema de admissão e extração de $\mathrm{CO}_{2}$, conforme o método proposto por EPSTEIN e MAYEDA (1953).

\subsection{Análise da relação $\mathrm{D} / \mathrm{H}$ $180 / 160$}

$\mathrm{Na}$ análise do conteúdo de $\mathrm{D}$ na amostra de hidrogênio, empregou-se o espectrômetro de massa da Varian-Mat modelo GD-150, existente nos laboratórios do Centro de Energia Nuclear na Agricultura (CENA) em Piracicaba, cujo desvio padrão na medida é da ordem de $1,5 \%$.

A deteç̧ão da relação isotópica $\mathrm{D} / \mathrm{H}$ através do referido espectrômetro foi feita empregando-se o método nulo, proposto por McKinney et alii (1950).

$\mathrm{Na}$ análise da relação $180 / 160 \mathrm{em}$ pregou-se o espectrômetro de massa MAT-230 da Varian-Mat, cujo erro padrão das medidas é da ordem de $0,2 \%$. A detecção da relação $180 / 160$ foi feita de modo semelhante ao empre. gado para a relação $\mathrm{D} / \mathrm{H}$, ou seja pelo método nulo proposto por McKinney et alii (1950).

No presente experimento, os resultados das análises do teor de deutério e oxigênio 18 são expressos na forma de $\mathrm{SD}$ e $\mathrm{S}_{18}$, em relação ao padrão internacional SMOW (Standard Mean Ocean Water):

$$
\begin{aligned}
& (\mathrm{D} / \mathrm{H})-(\mathrm{D} / \mathrm{H}) \\
& { }^{8} \mathrm{D}=\frac{\text { amostra } \quad \text { SMOW }}{(\mathrm{D} / \mathrm{H})} 10^{3} \\
& \text { SMOW } \\
& \S_{18}=\frac{\left(18_{0} / 16\right)-\left(18_{0} / 16_{0}\right)}{\text { amostra SMOW }}-\overrightarrow{-3}^{3}
\end{aligned}
$$

\subsection{Amostras de solo do Nordeste}

Paralelamente, às análises feitas para a água do solo de acordo com o já exposto, foi coletada e analisada a água retida por solo da região nordestina. Essas amostras de solo, num total de 13 , foram retiradas do leito seco do riacho do Navio sendo que na ocasiåo o lençol freático encontrava-se a cerca de $40 \mathrm{~cm}$ a $50 \mathrm{~cm}$ de profundidade de acordo com a topografia do terreno. No sentido transversal ao leito retirou-se amostras de 5 pontos distintos, distanciados de cerca de 5 metros um do utro. 
No primeiro e segundo pontos obteve-se amostras das camadas de 10 a 20 e de 30 a $40 \mathrm{~cm}$ de profundidade, altura esta em que se encontrava o lençol freático, em relação à superfície do solo e para os pontos 3, 4 e 5 além das camadas citadas, retirou-se também para a camada de 50 a $60 \mathrm{~cm}$. Para estes últimos pontos, o lenço freático situava-se a 60 $\mathrm{cm}$ de profundidade em relação à superfície do solo. $\mathrm{Na}$ figura 3 , apresentase a planta e, em corte a secção transversal do local, onde coletou-se as amostras descritas.

Na extração da água do solo, preparo para análise e análise do teor de deutério e oxigênio 18 seguiu-se a mesma metodologia descrita para o caso do experimento realizado com as colunas de solo.

\section{RESULTADOS}

No Quadro I estão apresentados os resultados da variação do $\mathrm{SD}_{\mathrm{D}} \mathrm{S}_{18} \mathrm{da}$ água extraída das colunas de solo, em função da profundidade e tempo de evaporação.

A água utilizada no suprimento dessas colunas apresentou um valor de $46,0 \%$ para $S_{D}$, valor médio de duas amostragens feitas no início do experimento.

O Quadro II apresenta os resultados preliminares das variaçðes de $\mathrm{SD}$ e $\mathrm{S}_{18}$ da água retida pelo solo da região nordestina, no leito seco do riacho $\mathrm{Na}$ vio, conforme descrição feita em Material e Método.

$O$ desvio dos dados apresentados no Quadro I é da ordem de $\pm 2,3 \%$ e \pm $0,5 \%$ e para o Quadro II, igual a \pm $6,2 \%$ e $\pm 1,9 \%$, respectivamente para os dados de SD e S18.

No Quadro III estão observadas, para as colunas de solo as respectivas variações do teor de umidade, à base de peso seco, em função da profundidade e tempo.

\section{DISCUSSÃO E CONCLUSÕES}

O experimento conduzido por LEOPOLDO et alii (1974) refere-se a colunas de solo saturadas uma única vez e colocadas sob condições naturais de evaporação até que o teor de umidade se tornasse constante.

No presente experimento, semelhan. tes colunas foram submetidas ao processo de perda de água, sob condiçð̃es de fornecimento contínuo de água durante todo o período, através de um lençol freático mantido a uma profundidade constante, sem variação da umidade do solo durante o período, conforme mostra os dados do Quadro III.
Pelos dados obtidos, relacionados no Quadro I pode-se observar que os resultados se assemelham aqueles obtidos por LEOPOLDO et alii (1973) ou seja, que a água do solo retida a baixos potenciais não são passíveis de sofrerem fracionamento isotópico, quanto ao teor de deutério e oxigênio 18 .

Desse modo, a passagem da água pelo solo, ou seja, o fluxo das camadas inferiores para as superiores e conseqüente perda para a atmosfera é feita sem que haja, praticamente, alteraçðes en seu conteúdo isotópico.

Observa-se, no entanto, que a camada superior (Qadro I), tem seus valores diferindo, em parte, da água de saturaçăo $\left(S_{d}-46 \%\right)$, apresentando um pequeno enriquecimento no conteúdo de deutério,, o qual segundo ZIMMERMANN et alii (1966), deve ser tåo maior quanto menor for a camada superficial observada.

No caso de plantas, o fato se dá de maneira semelhante. Segundo observa. çôs feitas por GONFIANTINI et alii (1963) e ZIMMERMANN et alii (1966) a água da planta se move através de vasos capilares sem que haja fracionamento isotópico da mesma. Para a água das folhas, no entanto, ocorre um enriquecimento no conteudo de deutério, por ocasiăo de sua perda por transpiração, para a atmosfera, conforme apresentaçåo feita por LEOPOLDO (1973).

Desse modo, a água que se move, no solo, através do sistema horizontes profundos - horizontes superficiais - ar comporta-se de maneira semelhante $d$ água envolvida no sistema solo-troncofolhas-ar, havendo um enriquecimento onde há evaporação direta do ar atmosférico, dando-se o transporte de água até a interface solo-ar ou folha-ar por capilaridade.

O presente experimento foi conduzido de modo a simular determinadas condiçðes semelhantes às de regióes semi-aridas do Nordeste Brasileiro, onde secam os rios, formando um leito seco, com o lençol freático a pequena profundidade. Esse lençol freático é aproveitado através da abertura das chamadas "cacimbas", das quais se aproveita a água para uso doméstico e outros como no provimento de animais. No entanto, essa água apresenta-se em alguns casos salina, e conseqüientemente impropria para tais usos.

O mecanismo de salinização das águas subterrâneas da região nodestina tem sido estudado por inúmeros pesquisadores, entre os quais SALATI e et alii (1970), que apontam a possibilidade de utilização de isótopos estáveis, na pesquisa de tais problemas.

SALATI et alii (1971) fizeram um levantamento das concentraçðes de 180 e D em águas subterrâneas e pluviais de regioes do Nordete e admitiram que a salinização das águas do Nordeste parece estar relacionado com o mecanismo da evapotranspiraçåo antes da recarga dos aquíferos.

Como pode ser observado pelos experimentos já realizados, a água do solo deve ser evaporada, sem que haja profundas alteraçðes no conteúdo isotopico da água residual.

No entanto, numa análise preliminar, pelos resultados apresentados no Quadro II, pode ser observado que ocorre um certo fracionamento isotópico com relação ao hidrogênio e oxigênio, até certo ponto bastante acentua do.

Observa-se ainda que o fracionamento ocorre tanto no sentido das laterais para o centro do rio, como também no sentido ascendente, ou seja, das camadas mais profundas para as camadas superficiais. A relação entre as concentraçōes de $D$ e 180 para a água subterrânea da região cristalina, conforme SALATI et alii (1971) é a seguinte:

$$
{ }^{8} \mathrm{D}=6,68_{18}+3,8 \ldots \ldots \ldots
$$

Para a água do solo da regiăo nordestina tem-se a seguinte relação:

$$
\delta_{D}=2,8{ }_{18}{ }_{18}-6,3 \text { (solo do Nor- }
$$

deste $) \ldots \ldots \ldots \ldots \ldots \ldots \ldots \ldots$

Pode-se observar, pelos coeficientes angulares das equações 1 a 2 que a água do solo em relação à água subterrânea sofreu uma intensa evaporação.

Os dados obtidos por LEOPOLDO (1973), para colunas de solo arenoso, saturadas e submetidas ao processo de evaporação apresentou a seguinte rela ção:

$$
{ }^{8_{D}}=3,2^{8_{18}}-28,2 \ldots \ldots \ldots
$$

Observa-se que os coeficientes angulares das equações 2 e 3 săo ligeiramente semelhantes. Graficamente, tais correlaçðes såo apresentadas na figura 4,5 e 6 , respectivamente.

Os resultados do Quadro II bem como as análises das relações $S_{D}-S_{18}$ indicam uma evaporação intensa e estão concordes com a apresentação feita por SALATI et alii (1971) para os aquíferos do cristalino, regiao da qual experimento. "Nos aquíferos do cristalino, as amostras analisadas apresentaram uma relação $D-180$ indicativa de que as aguas dos mesmos sofreram evaporação".

Tais resultados, no entanto, e apesar de preliminares, dåo boas razões para se continuar os estudos da água do solo na regiåo, através da utilização de isótopos estáveis.

Evidentemente, melhores resultados poderăo ser obtidos desde que se tome 
en particular o estudo de uma bacia, através de maiores observaçðes e correlaçoes entre água do solo, água de chuva e água subterrânea, além da ob- tençáo de outros dados que possibilitem uma melhor compreensão dos resultados.

Un estudo dessa natureza poderá trazer maiores esclarecimentos com relaçăo d̀ dinâmica das águas, salinizaçăo e porque do presente fracionamento para a água do solo.

\section{BIBLIOGRAFIA}

GONFIANTINI, R., TOGLIANTTI, $v$ e ToTONGIORGI, E. 1963, Some possible aplica tions of isotopic analyses of water to hydrologic problems. Consiglio Nazionale Delle Ricerche, Roma $71-80$.

LEOPOLDO, P.R. 1973. Fracionamento isotópico da água do solo e da planta. Tese de Doutoramento apresentada à FCMBB, Botuca$1 \mathrm{u}, 104 \mathrm{p}$.

$$
\text { SALATI, E e MATSUI, E. } 1973 .
$$

Método de extraçào da água do solo para análise da relaçåo $\mathrm{D} / \mathrm{H}$. Piracicaba, CENA, Boletim no $9,21 \mathrm{p}$.

1974. Fracionamento isotópico da árua do solo durante o processo de evaporação. Ciência e Cultura, 26(7): 668-671

MATSUI, E., SALATI E. e FERRAZ, E.S.A. 1971. Medida da variaçao natural da relação D/H em amostras de água. Piracicaba, CENA, Boletim n० $1.31 \mathrm{p}$

MICKINNEY, C.R., MCCREA, J.M. EPS. TEIN, S., HALLEN, H.A, E UREY, H.C. 1950. Improvements in mass spectrometers for the measurement of small differences $i$ isotope abundance ratios. The Review of scientific instruments, 21 (8): $724-730$.

SALATI, E, MOURA NETO, M.R. CERVELIINI, A. 1970. Concentraça de $180 \mathrm{em}$ aguas subterrâneas do Nordeste Brasileiro, Relatório Preliminar - CENA-ESALQ-USP (não publicado)

SALATI, E. GUSMÃO, G.A., MATSUI, E. CERVELLINI, A., $19 \phi_{0}^{\circ}$ Estudomptriminto

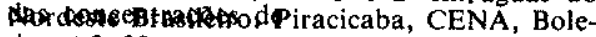
tim $n^{\circ} 2,30 p$

ZIMMERMAN, U., EHHALT, D. E MUNNI CH, K.O. 1966. Soil water movement and evapotranspiration: changes in the isotopic compositions of the water. In Symposium of Isotopes in Hydrology. I.E.A.A., Vienna, 14 a 18 de novembro de $1966,567.585$. 


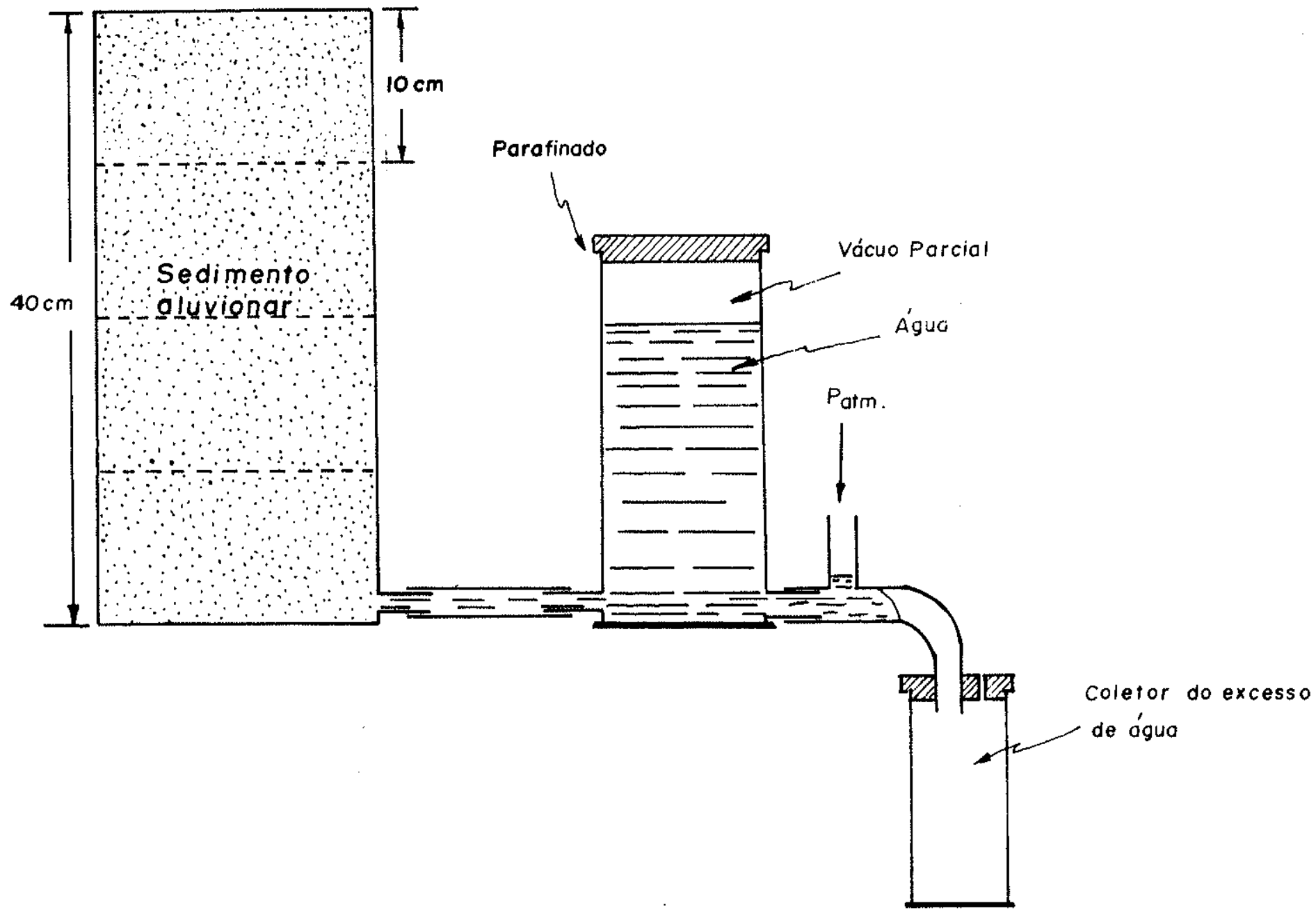

FIG. I - Coluna de solo e sistemo de suprimento de água a carga constante.

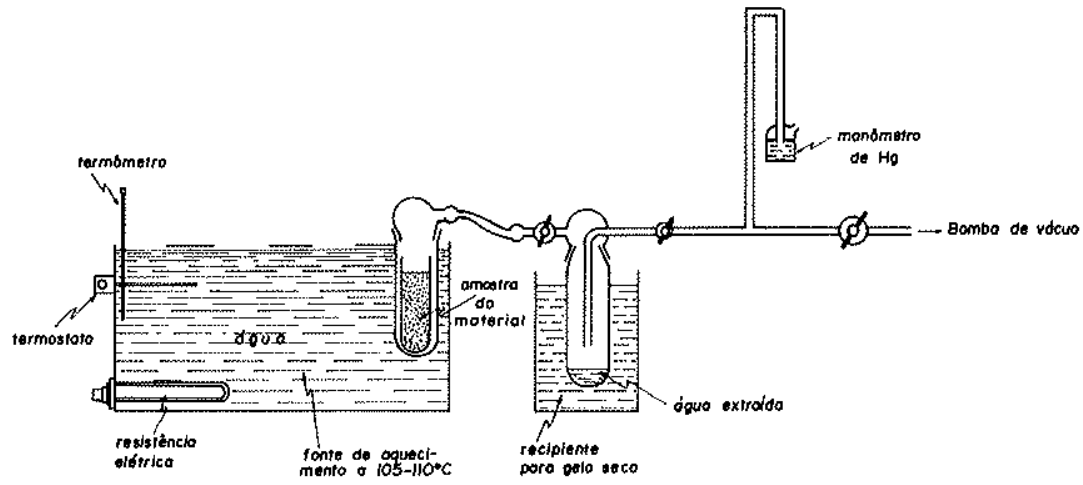

FIG. 2 - Esquemo do sistema de extrasdo da ́́, quo do solo

(capacidade paro 8 amostross simúrâneos). 
QUADRO I - Varlação dos valores de $80 \%, 8818$ da água extralda das colunas

de solo. com lençol treático constante a $40 \mathrm{~cm}$ de profundidade.

Profundiogde Coluna A 17 dias! Coluna 8114 diasl Coluna C 121 dias $\quad$ Coluna 0 (28 dias) Coluna E 135 dias)

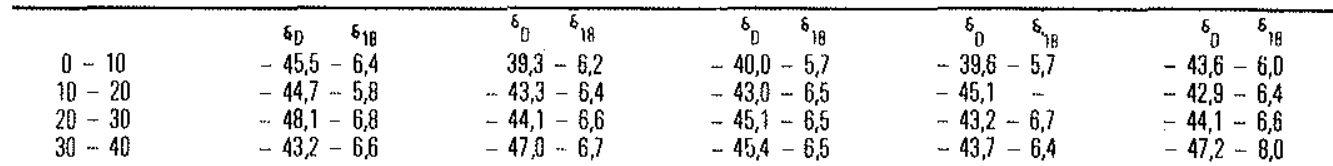

QUADRo II - Varlação de $\delta_{0} \%_{0} \in \delta_{18} \%$ da água do solo, no lelito seco do rlo

Profundidade

Ponto I

Ponto 2

Ponto 3

Ponto 4

Ponto 5

$\delta_{0} \quad \delta_{18}$

$\delta_{0} \delta_{18}$

$\delta_{D} \delta_{H B}$

${ }_{0}^{5} \quad{ }_{18}$

$\sigma_{0} \quad \delta_{18}$

$-9,6-1,4$

$-13,4$
$-12,6-2,3$

$-14,2-3,7$

$-17,3-4,4$

$-16,9-3,6$

$-12,6=$

$-19,2-3,0$

\section{QUADRO III - Variação do teor de unidade do solo, em \% à base de peso, seco das colunas}

\begin{tabular}{rrrrrr} 
Profundidade & Coluna A & Coluna B & Coluna C & Coluna D & Coluna E \\
\hline & & & & & \\
$0-10$ & 8,5 & 9,8 & 9,5 & 8,8 & 8,0 \\
$10-20$ & 13,0 & 14,5 & 14,9 & 12,7 & 13,0 \\
$20-30$ & 15,0 & 14,0 & 15,4 & 14,9 & 14,0 \\
$30-40$ & 16,0 & 15,5 & 16,0 & 16,2 & 16,0
\end{tabular}




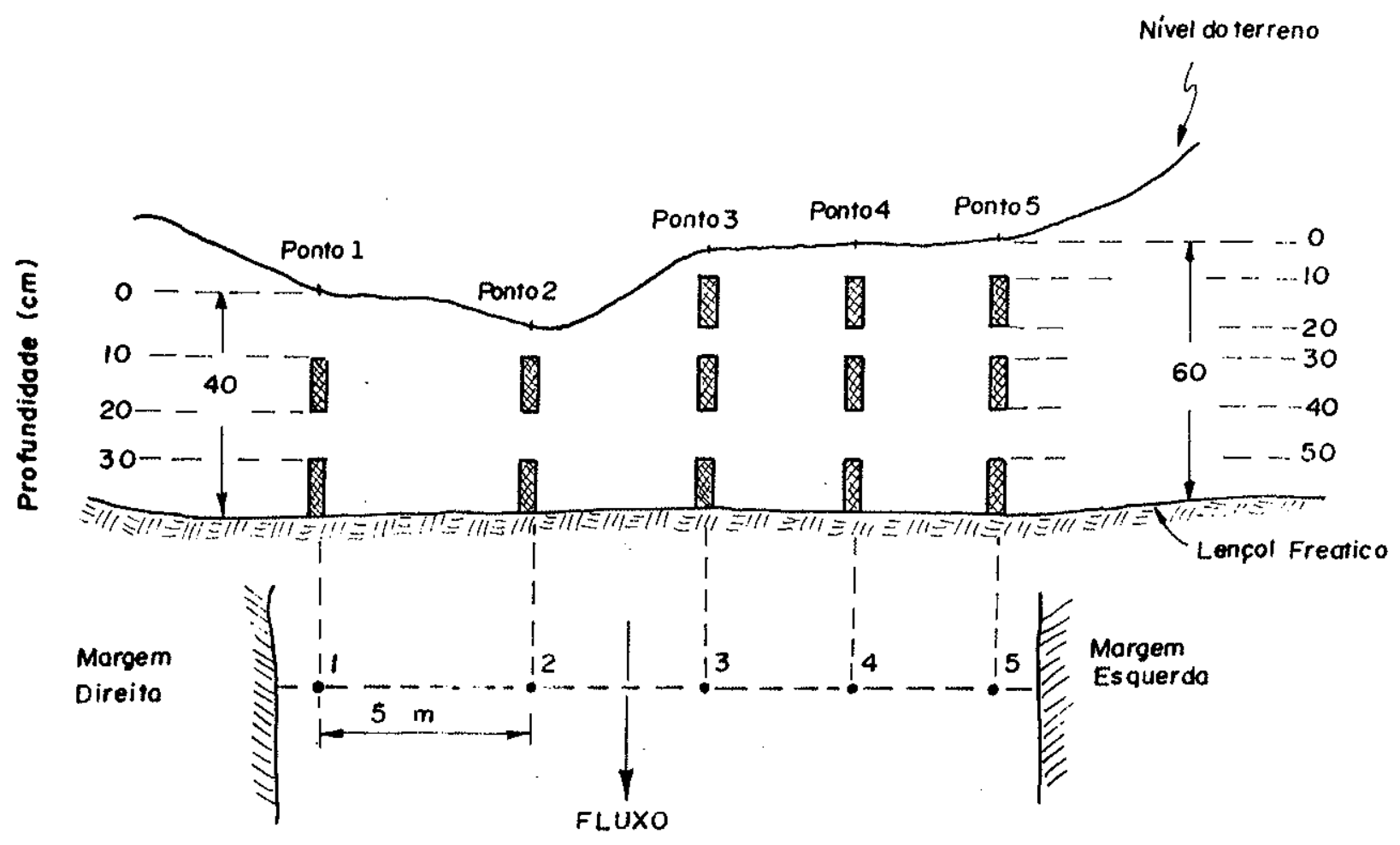

FIG.3 - Planta e corte transversal do rio, com leito seco, apresentando em esquema os pontos de coleta de amostro de soto.

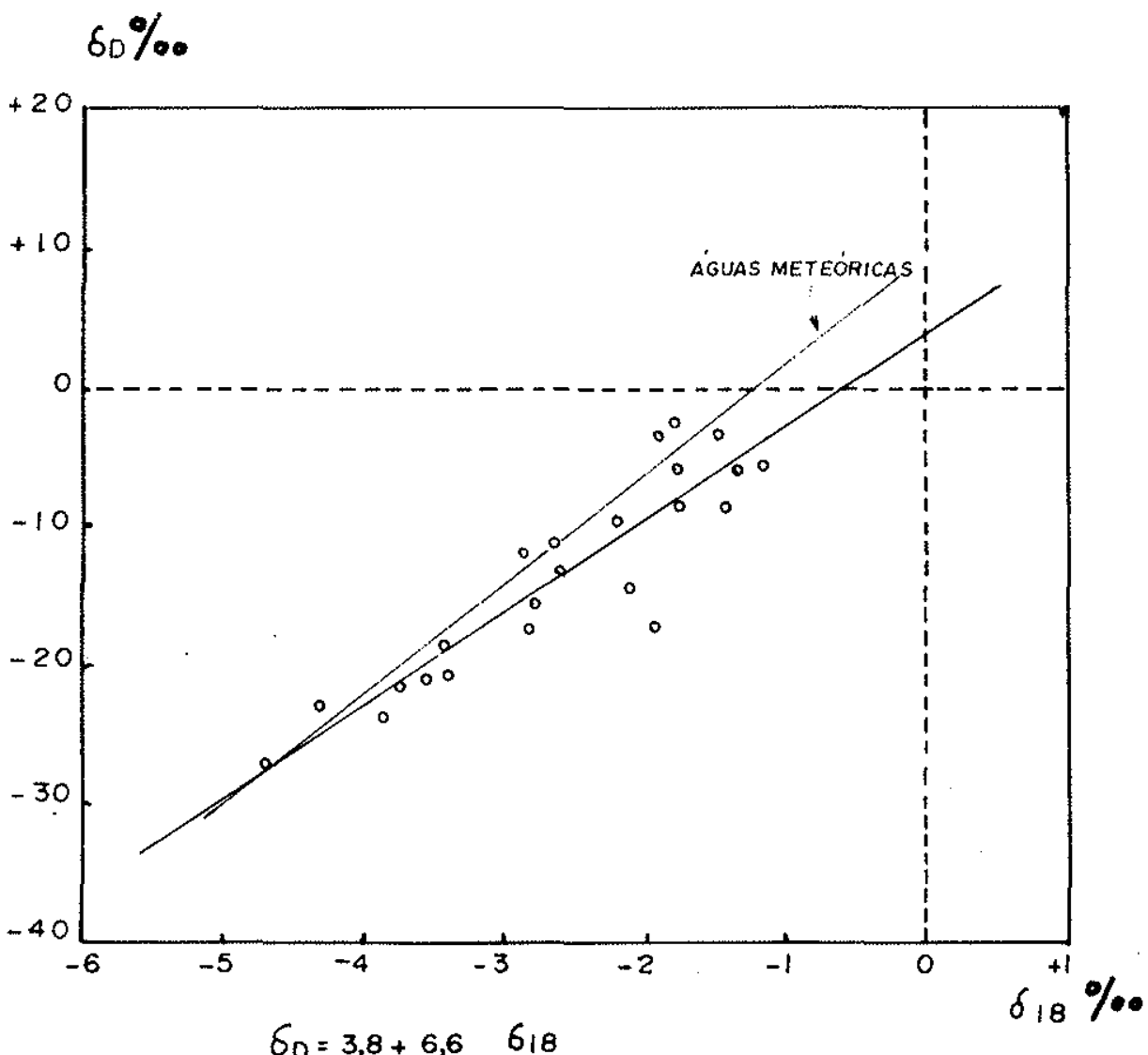

\footnotetext{
FIG. 4 - CORRELAÇão das CONCENTRAÇŌEs de D E ${ }^{18} \mathrm{O}$ EM ÁGUAS SUBTERRÃNEAS NAS REGIÖES DE FORMAÇÃO CRISTALINA NO NORDESTE BRASILEIRO.
} 


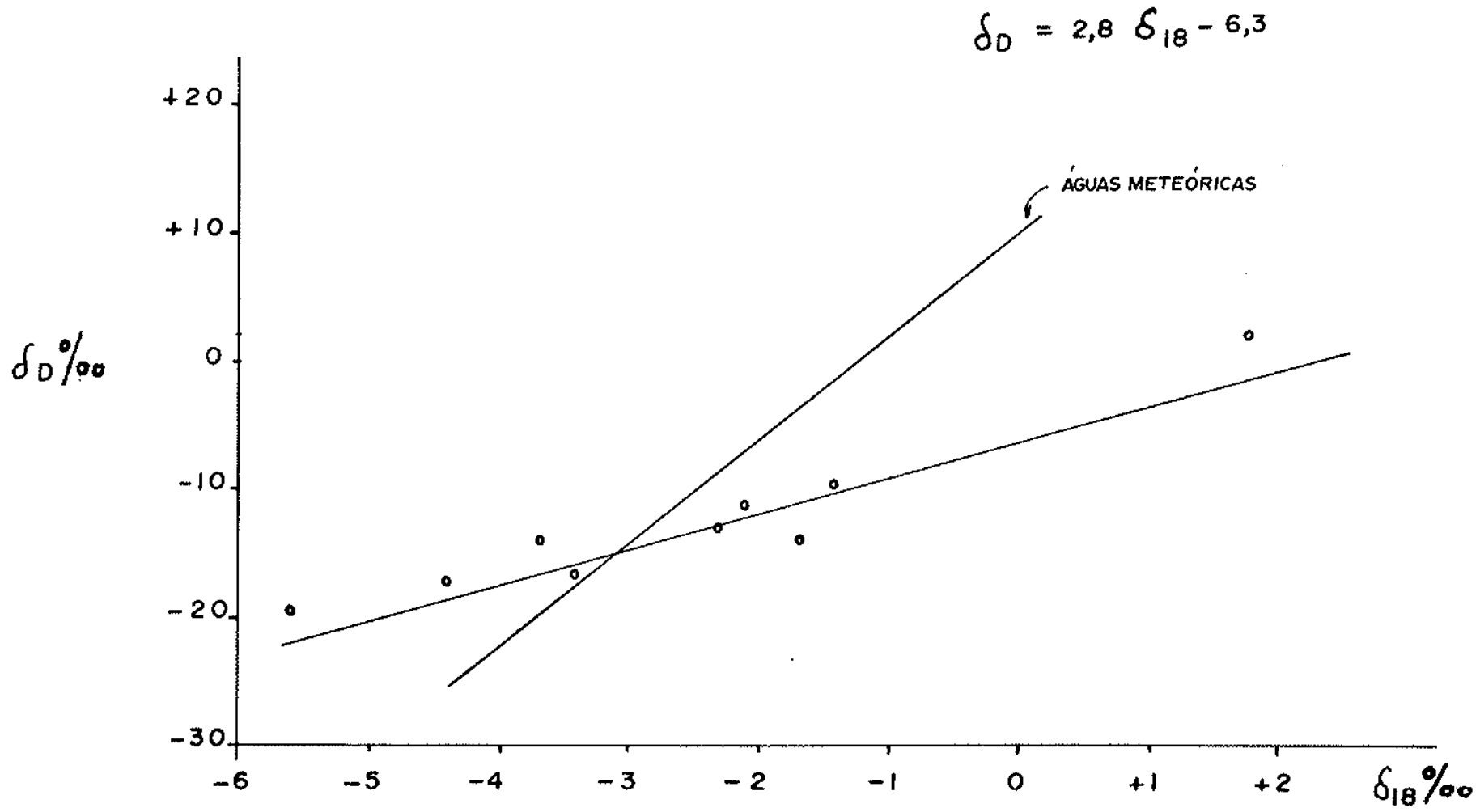

FIG.5 - CORRELAÇÃo dAS CONCENTRAÇÕES DE D E 18 EM ÁGUA do SOLO DA REGIÃo NORdESTINA (RIACHO dO NAVIO - LEITO SECO)

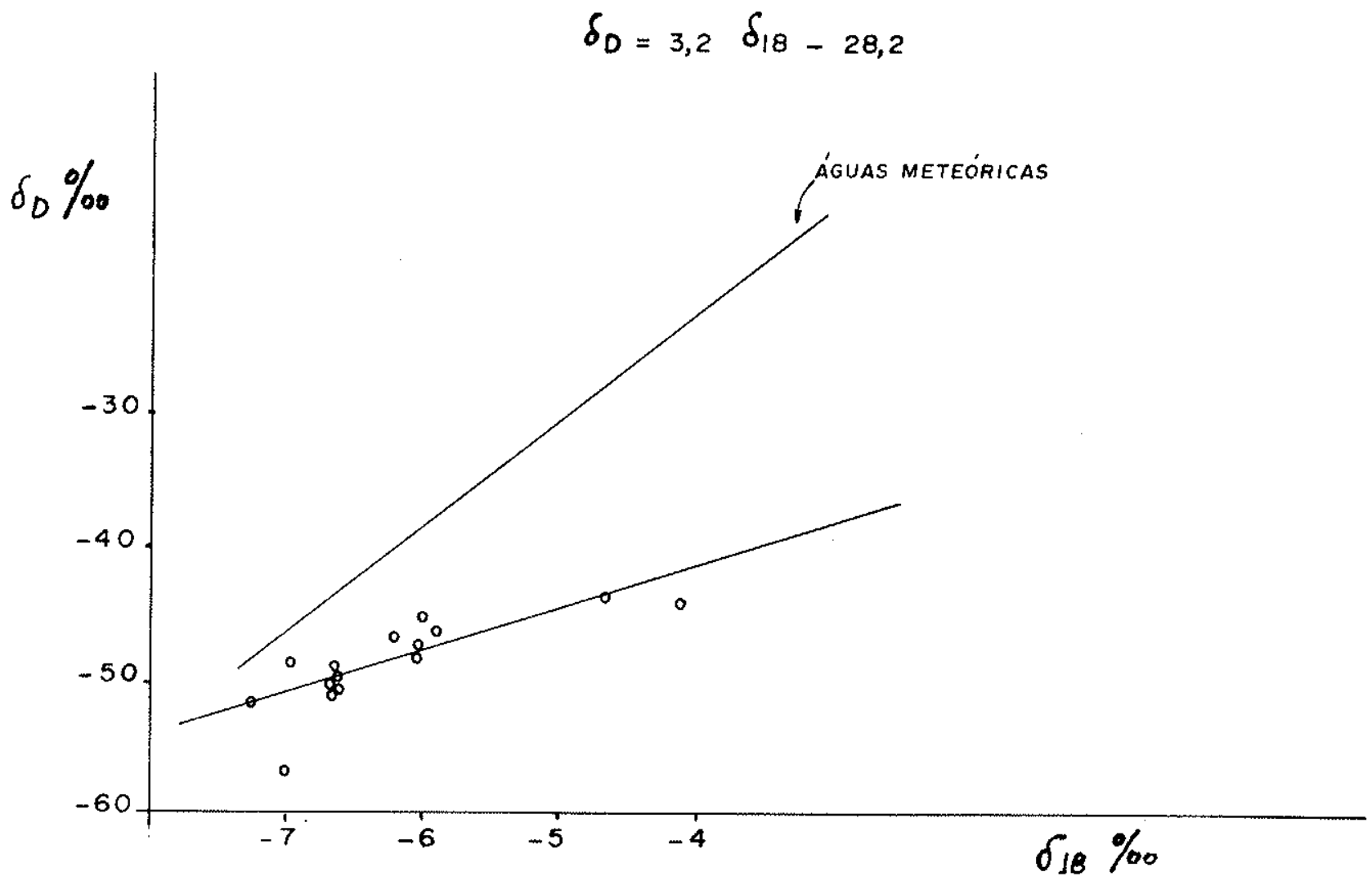

FIG.6- CORRELAÇÃo de D E ${ }^{18}$ o EM ÁGUa extraída de colunas de solo ARENOSO, SATURADAS E SUBMETIDAS AO PROCESSO DE EVAPORAÇÃo. 